\title{
Персистирующая интерстициальная эмфизема легких: морфология, принципы диагностики и лечения
}

1 - СПбГУЗ "Детская городская больница № 1": 198205, Санкт-Петербург, ул. Авангардная, 14;

2 - Санкт-Петербургская государственная педиатрическая академия: 194100, Санкт-Петербург, ул. Литовская, 2;

3 - ГОУ ДПО "Санкт-Петербургская медицинская академия последипломного образования Росздрава": 191015, Санкт-Петербург, ул. Кирочная, 41

\section{S.D.Popov, S.A.Karavaeva, T.V.Omelchenko, N.A.Ilyina \\ Persistent interstitial emphysema of the lung: morphology, diagnosis and treatment}

Key words: interstitial emphysema, newborns, congenital cystic malformations, computed tomography.

Ключевые слова: интерстициальная эмфизема, новорожденные, врожденные кистозные мальформации, компьютерная томография.

В последние годы все больше детей рождаются недоношенными, в т. ч. с критически низкой массой тела. В связи с этим врачи отделений интенсивной терапии сталкиваются со специфическими проблемами, одна из которых - эффективное лечение респираторного дистресс-синдрома (РДС) и интерстициальной эмфиземы (ИЭ). ИЭ чаще всего является следствием искусственной вентиляции легких (ИВЛ) при РДС. Хотя в некоторых случаях возможно развитие этого состояния и без ИВЛ $[1,2]$. В патогенезе ИЭ основное значение имеет повреждение легочной ткани (разрывы), что приводит к попаданию воздуха или кислородной смеси в интерстициальное пространство. Газовая смесь может проникать в интерстициальное пространство, расширяя его и образуя полости различного диаметра, которые при рентгенологическом или секционном исследовании выглядят, как пузырьки (буллы) [3].

Выделяют острую и персистирующую ИЭ. Острой ИЭ считается в течение первых 7 дней с момента первых клинических проявлений, позже процесс рассматривают уже как персистирующую ИЭ. Кроме того, по распространенности ИЭ может быть диффузной (в нескольких долях) и локализованной (в 1 доле).

Основными осложнениями острой ИЭ являются: пневмоторакс, "воздушный замок", пневмоперитонеум, пневмоперикард, пневмомедиастинум, системная воздушная эмболия. Термин "воздушный замок" используют для обозначения состояния, когда воздух, накопившийся в области ворот легких, вызывает компрессию сосудов, что приводит к выраженному нарушению легочного кровотока, резкому нарушению газообмена в малом круге кровообращения - вплоть до летального исхода [3-5].

Развитие интерстициальной эмфиземы, преимущественно в 1 легком, также приводит к появлению булл, смещению средостения и компрессии проти- воположного легкого. Таким образом, интерстициальная эмфизема усиливает гипоксию у детей с серьезными нарушениями газообмена.

Морфологически ИЭ проявляется широкими междольковыми перегородками с многочисленными пузырьками газа. На разрезе в легких также видны широкие интерстициальные пространства. При гистологическом исследовании в интерстициальных пространствах определяются полости, в которых со временем можно наблюдать гигантоклеточную реакцию. Появление гигантских клеток типа клеток инородных тел объясняется тем, что воздух является "инородным телом" в данной локализации, вызывая макрофагальную реакцию.

Позже вокруг полостей возникает инфильтрация, представленная преимущественно лимфоцитами, и формируется фиброзная капсула, на внутренней поверхности которой определяются многоядерные клетки. В этом случае можно судить о персистирующей ИЭ. Именно характер фиброзной капсулы и наличие многоядерных клеток при отсутствии эпителиальной выстилки позволяют отличить персистирующую ИЭ от врожденных легочных аномалий и, прежде всего, врожденной кистозной аденоматоидной мальформации [6].

В качестве клинических примеров приводем 2 наблюдения детей с различными вариантами течения ИЭ.

Ребенок мужского пола родился на 34-й нед. беременности, протекавшей без особенностей. Масса тела при рождении - 2300 г, оценка по шкале Apgar - 5-6 баллов. В родильном зале была выполнена интубация из-за тяжелой дыхательной недостаточности (ДН), и в возрасте 4 ч ребенок был переведен в отделение реанимации Центра патологии новорожденных Санкт-Петербурга с тяжелым РДС. Первые 5 сут. находился на высокочастотной вентиляции легких, затем в течение следующих 9 сут. проводилась традиционная вентиляция. На 6-е сут. на фоне ИВЛ с мягкими параметрами диагностирован левосторонний пневмоторакс, источником которого явилась киста, появившаяся в проекции нижней доли левого легкого. Компьютерная томография (КT) груди также 
подтвердила наличие кисты диаметром 2,0 см с толстыми, неровными стенками и умеренным объемным воздействием в 9-10-м сегментах нижней доли левого легкого (рис. 1). На 14-е сут. жизни ребенка была проведена экстубация. Однако в течение следующих 2 нед. наблюдался быстрый рост кисты (до 3,5 см в диаметре), при этом состояние ребенка оставалось относительно стабильным. Тем не менее, учитывая прогрессирующий рост кисты, угрозу пневмоторакса и подозрение на врожденную кистоаденоматозную мальформацию I типа нижней доли левого легкого, было принято решение о необходимости операции. На операции обнаружено, что практически вся нижняя доля представлена полостью кисты, имеющей хорошо выраженную капсулу. Киста занимала практически всю удаленную долю легкого, с узким ободком легочной ткани по периферии.

При морфологическом исследовании обнаружено, что стенка кисты представлена фиброзной тканью с большим количеством коллагена и фибробластами. Киста не имела эпителиальной выстилки, однако на внутренней поверхности капсулы кисты отчетливо определялись многоядерные клетки, что является характерным признаком персистируюшей ИЭ.

Послеоперационный период протекал гладко, и на 10-е сут. ребенок в возрасте 1 мес. 23 дней был выписан домой в удовлетворительном состоянии под наблюдение пульмонолога диспансера.

Во 2-м наблюдении ребенок был также прооперирован с подозрением на порок легкого в возрасте 21 дня. Девочка родилась

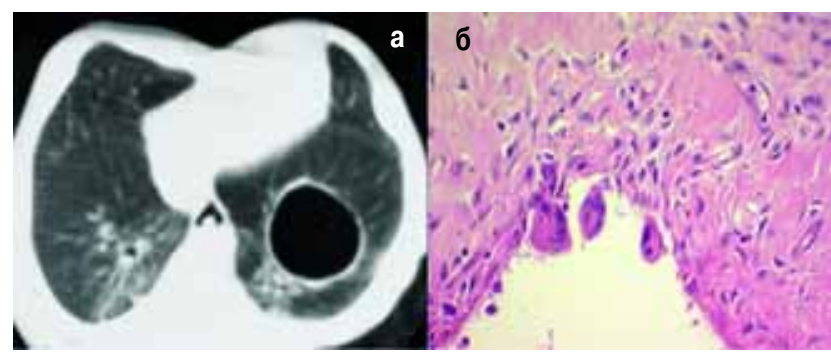

Рис. 1: а - КТ грудной клетки на уровне базальных отделов легких: в S9-10 нижней доли левого легкого определяется киста диаметром 2,0 см с толстыми, неровными стенками и умеренным объемным воздействием; б - гистологически выявляется фиброзная капсула без эпителиальной выстилки, но с наличием многоядерных клеток на внутренней поверхности (окраска гематоксилином и эозином; × 400)

путем кесарева сечения на сроке 35-36 нед., масса при рождении 2310 г. Состояние было тяжелым: выраженная ДН потребовала проведения высокочастотной ИВЛ. На фоне ИВЛ с жесткими параметрами возник 2-сторонний пневмоторакс, который был дренирован. Улучшение отмечено к 4-м сут. жизни, что позволило перевести ребенка на вспомогательную вентиляцию легких и экстубировать на 11-е сут. жизни. С 16-го дня жизни девочка не нуж-

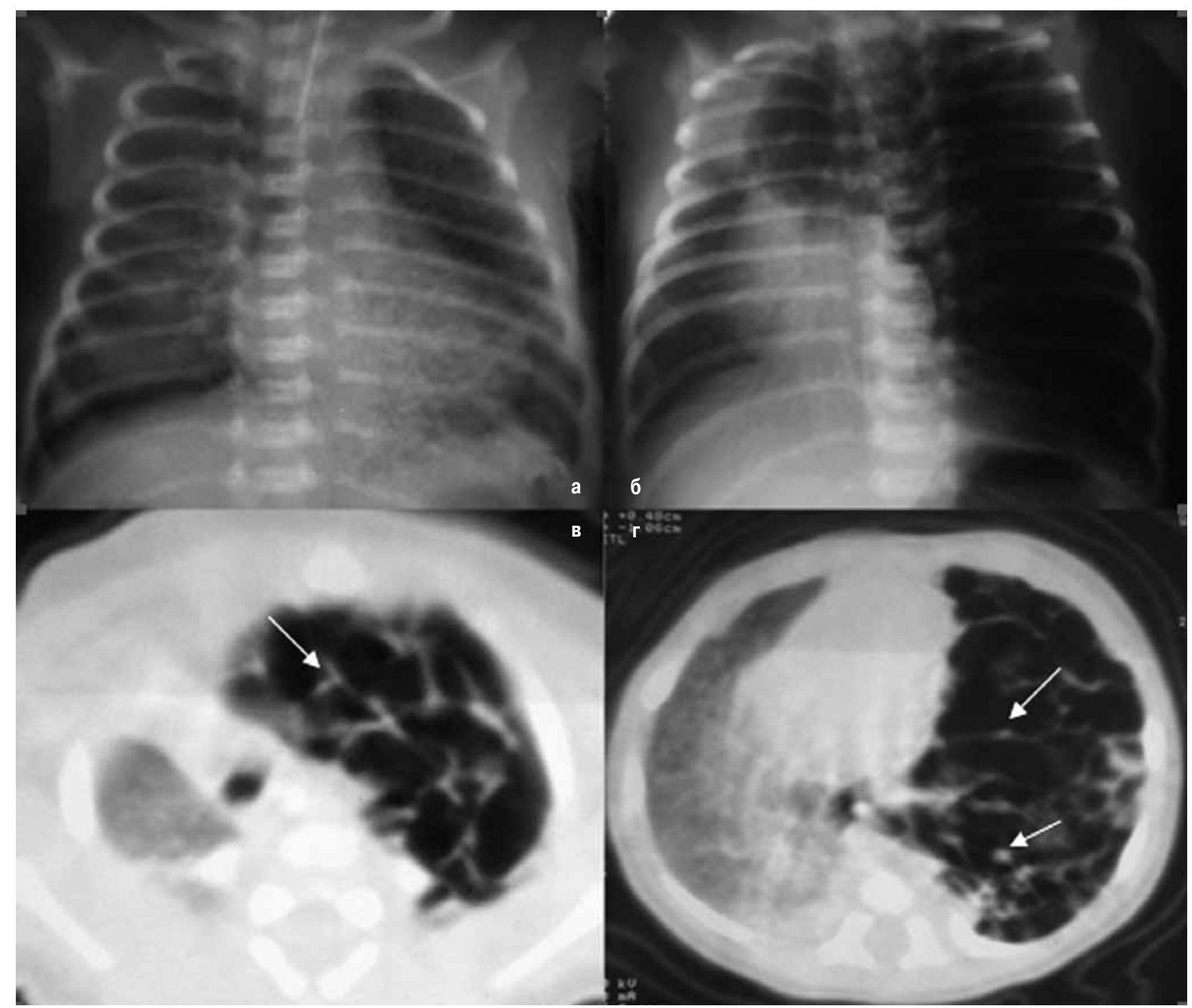

Рис. 2: а - рентгенограмма грудной клетки новорожденной девочки в возрасте 2 дней жизни: неоднородная воздушность левого легкого; б - рентгенограмма грудной клетки девочки в возрасте 20 дней жизни: увеличение объема левого легкого с выраженным масс-эффектом, резкое смещение средостения вправо; в, г - КТ грудной клетки: кистозные изменения в левом легком с наличием точечных и линейных структур, резкое смещение трахеи и органов средостения вправо, объем правого легкого уменьшен 


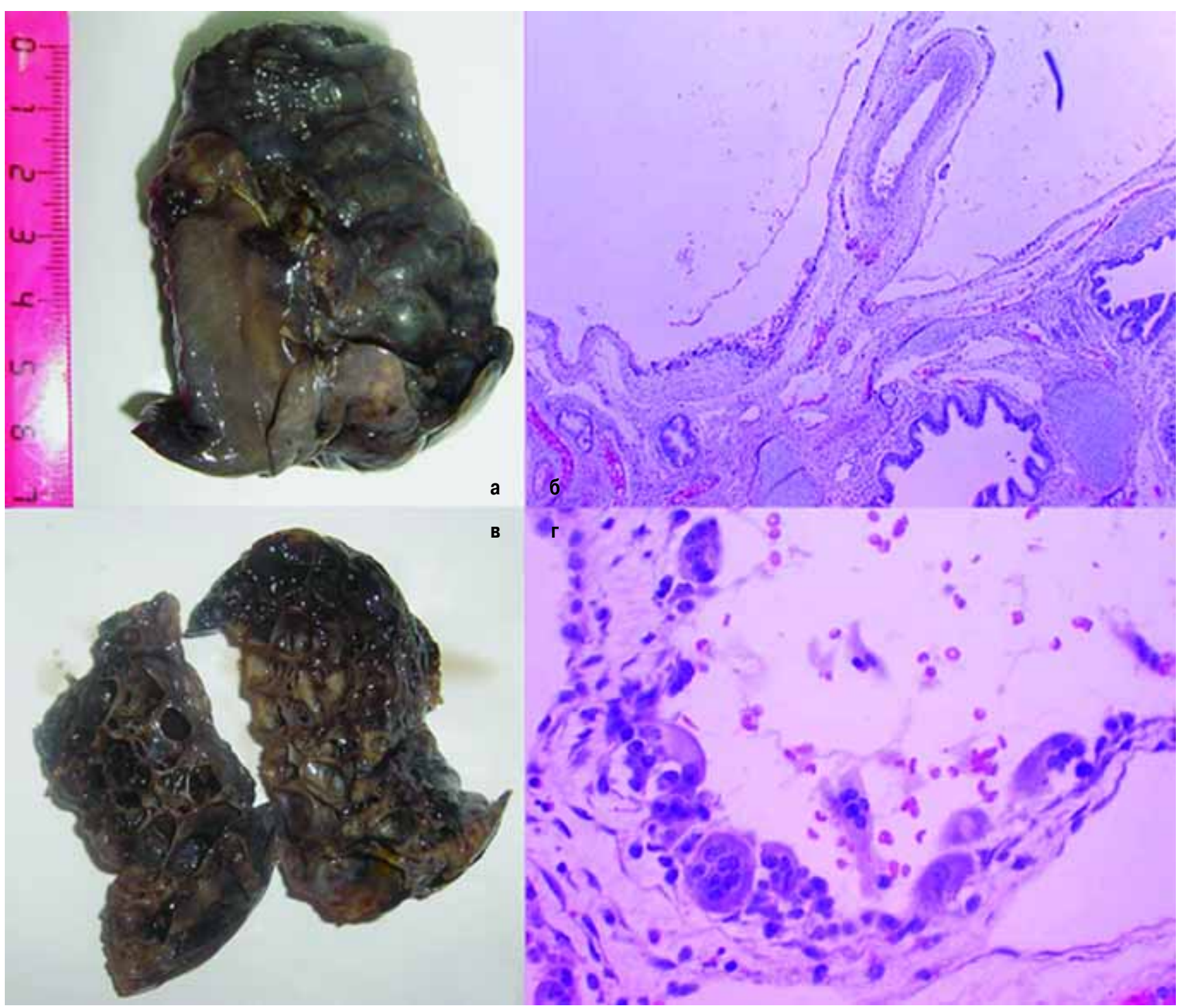

Рис. 3: а, б - многочисленные кистозные образования в удаленном легком, практически неотличимые от таковых при кистозной аденоматоидной аномалии; в, Г - гистологически выявляются кистозные полости, лишенные эпителиальной выстилки, во многих из них определяются гигантские многоядерные клетки, а в некоторых - сосудисто-бронхиальные тракты, соответствующие линейным и точечным структурам на КТ (окраска гематоксилином и эозином; × $100 ; \times 400$ )

далась в дополнительной кислородной поддержке, хотя сохранялось тахипноэ до 60-70 мин ${ }^{-1}$. К 20-му дню жизни состояние ребенка вновь ухудшилось за счет нарастания ДН, появления эпизодов апноэ с разлитым цианозом.

На рентгенограмме грудной клетки, выполненной на 2-е сут. жизни, определялась неоднородная воздушность левого легкого с чередованием участков локального вздутия и мелких ателектазов. Средостение не было смещено, в полости плевры справа определялось небольшое количество воздуха. В динамике рентгенологическая картина характеризовалась значительным вздутием левого легкого с наличием множества мелких кист по всему левому легочному полю, нарастающим смещением средостения, достигшим максимума к 20-м сут. жизни ребенка, уменьшением объема правого легкого.

КТ груди на 21-е сут., выполненная по экстренным показаниям, позволила выявить резкое увеличение объема левого легкого, при этом практически все легкое было представлено воздушными кистами округлой и неправильно овальной формы размером от 0,4 до 1,2 см с наличием линейных или точечных структур в некоторых из них. Органы средостения были значительно смещены вправо, а объем правого легкого уменьшился (рис. 2).

Нарастающая ДН с непосредственной угрозой жизни ребенка потребовала скорейшего оперативного вмешательства. Во время операции обнаружено тотальное поражение левого легкого с наличием в нем многочисленных кист. Была произведена левосторонняя пульмонэктомия. Послеоперационный период протекал гладко. Ребенок хорошо адаптировался к дыханию одним легким, а отсутствие объемного воздействия на средостение улучшило и механику и гемодинамику дыхания. Девочка была выписана под наблюдение пульмонолога на 15-е сут. после операции в удовлетворительном состоянии, без признаков ДН.

Удаленное легкое содержало многочисленные кисты до 1,2 см в диаметре, и по макроскопическим признакам патология напоминала врожденную кистозную аденоматоидную мальформацию. Гистологически ткань характеризовалась наличием многочисленных полостей с выраженной гистиоцитарной и гигантоклеточной реакцией, что, несомненно, указывало на вторичный характер изменений при ИЭ (рис. 3).

\section{Заключение}

Персистирующая ИЭ является тяжелым осложнением РДС, способного как самостоятельно, так и в сочетании с другими заболеваниями привести к летальному исходу. Диагностировать эту патологию достаточно трудно, т. к. в ряде случаев она сходна с врожденными кистозными аномалиями легких. Иногда только гистологическое исследование позволяет установить характер поражения. Однако тщательный 
анализ клинической картины и данных КТ помогает провести дифференциальную диагностику. При персистирующей ИЭ на КТ обычно видны многочисленные воздушные полости. В них можно определить точечные или линейные структуры, вдающиеся в просвет полостей и морфологически соответствующие сосудисто-бронхиальным пучкам.

Еще одним заболеванием легких, которое необходимо отличать от персистирующей ИЭ, является диффузная легочная лимфангиэктазия, при которой кистовидно расширенные лимфатические сосуды выявляются как в междольковых септах, так и субплеврально. Рентгенологически при диффузной легочной лимфангиоэктазии обнаруживаются интерстициальные сетчатые затемнения, которые могут сочетаться с хилотораксом, в то время как при ИЭ полости выглядят прозрачными, т. к. заполнены только воздухом.

Дифференциальная диагностика ИЭ и врожденных аномалий легочной ткани важна, прежде всего потому, что тактика лечения этих заболеваний различна. При ИЭ, учитывая возможность регресса данной патологии, возможна консервативная терапия. При локализованных формах может быть эффективным создание соответствующего положения больного, которое будет препятствовать экскурсии грудной клетки на стороне поражения в сочетании с селективной бронхиальной интубацией менее пораженного легкого [7, 8]. Хирургическое вмешательство является необходимым, если консервативная терапия не оказала должного действия или в случае рецидивов.

\section{Литература}

1. Dembinski J., Heep A., Kau N. et al. CT imaging of pulmonary lobar interstitial emphysema in a spontaneous breathing preterm infant. Am. J. Perinathol. 2002; 19 (6): 285-290.
2. Smith T.H., Currarino G., Rutledge J.C. Spontaneous occurrence of localized pulmonary interstitial and endolymphatic emphysema in infancy. Pediatr. Radiol. 2005; 14 (3): $142-145$.

3. King D.W., Sobin L.H., Stocker J.T., Wagner B. Non-neoplastic disorders of the lower respiratory tract. Fascicle 2. AFIP. Washington; 2002. 518-522.

4. Donelly L.F., Lucaya J., Ozelame V. et al. CT findings and temporal course of persistent pulmonary interstitial emphysema in neonates: a multiinstitutional study. Am. J. Roentgenol. 2003; 180: 1129-1133.

5. Agrons G.A., Courtney S.E., Stocker J.T., Markowitz R.I. From the archive of the AFIP: Lung disease in premature neonates: radiologic-pathologic correlation. RadioGraphics 2005; 25: 1047-1073.

6. Langston $C$. New concept in the pathology of congenital lung malformations. Semin. Pediatr. Surg. 2003; 12 (1): 17-37.

7. Schwartz A.N., Graham C.B. Neonatal tension pulmonary interstitial emphysema in bronchopulmonary dysplasia: treatment with lateral decubitus positioning. Radiology 1986; 161: 352-354.

8. Lewis $S$., Pelausa E., Ojah C., Paes B. Pulmonary interstitial emphysema: selective bronchial occlusion with a SwanGanz catheter. Arch. Dis. Child. 1988; 63 (3): 313-315.

\section{Информация об авторах}

Попов Сергей Дмитриевич - к. м. н., доцент кафедры патологической анатомии Санкт-Петербургской государственной педиатрической медицинской академии, зав. отделением патологической анатомии Детской городской больницы № 1; тел.: (812) 735-91-02; e-mail: sergdgb@mai.ru

Караваева Светлана Александровна - д. м. н., проф. кафедры детской хирургии Санкт-Петербургской медицинской академии последипломного образования Росздрава, врач-хирург Детской городской больницы № 1; тел.: (921) 984-61-75; e-mail: ivkaravaev@yandex.ru

Омельченко Татьяна Викторовна - аспирант кафедры детской хирургии Санкт-Петербургской медицинской академии последипломного образования Росздрава; врач-хирург Детской городской больницы № 1; тел. / Факс: (812) 735-99-98

Ильина Наталья Александровна - к. м. н., доцент кафедры лучевой диагностики Санкт-Петербургской медицинской академии последипломного образования Росздрава, врач-рентгенолог Детской городская больницы № 1; тел.: (812) 735-05-00; e-mail: ilyina-natal@mail.ru

Поступила 23.03.10 (с) Коллектив авторов, 2010 удК 616.24-007.63 